\title{
Acquired Factor V Inhibitor Responsive to Corticosteroids in a Patient with Double Cancers
}

\author{
Hitoshi Endo ${ }^{1}$, Kiyotaka Kawauchi ${ }^{1}$, Masahiko Tomimatsu ${ }^{1}$, Daijiro Iga ${ }^{1}$, \\ Toshie Ogasawara ${ }^{1}$, Masako Yasuyama ${ }^{1}$, Toshihito Saito ${ }^{1}$, \\ Kuniaki Otsuka ${ }^{1}$ and Motohiko Aiba ${ }^{2}$
}

\begin{abstract}
A 70-year-old woman suffering from HCV-related liver cirrhosis was admitted for abnormal bleeding. Laboratory findings included PT at $46.6 \mathrm{sec}$, APTT at $>212 \mathrm{sec}$, factor V activity of $<3 \%$, and factor V inhibitor of $2 \mathrm{BU}$. Having experienced a persistent bleeding tendency for one month, the patient was started on prednisolone $(0.8 \mathrm{mg} / \mathrm{kg} /$ day $)$. Within a few days, the inhibitor became undetectable and clinical bleeding disappeared. Although clinical improvement was achieved, she died 6 months after the initial bleeding episode from the progression of a lung cancer. An autopsy revealed squamous cell carcinoma of the lung and hepatocellular carcinoma.
\end{abstract}

Key words: factor V inhibitor, HCV, liver cirrhosis, hepatocellular carcinoma, lung cancer

(DOI: 10.2169/internalmedicine.46.6390)

\section{Introduction}

Acquired factor $\mathrm{V}$ inhibitors (FVIs) have been documented since the reports by Hörder et al in 1955 (1) and Ferguson et al in 1958 (2). In 2002, Streiff and Ness described 3 cases together with a systemic review of 126 cases retrieved through MEDLINE (3). The presence of FVIs is considered to be a rare event, while to our knowledge, 12 more cases (in English) and several cases in other languages have recently been reported.

Regarding the properties of inhibitors, it has been described that they are usually polyclonal IgG antibodies which interfere with the formation of the prothrombinase complex through binding to the $\mathrm{C} 2$ domain of the light chain of FV (4). FVIs seem to be preceded by various diseases or conditions, such as major surgery, especially when bovine thrombin or fibrin glue has been used or there has been exposure to antibiotics, autoimmune disorders, or malignant diseases. However, FVIs in conjunction with double cancers are quite rare. Here, we report an elderly patient suffering from HCV-related liver cirrhosis with HCC, who succumbed to lung cancer after successful treatment with prednisolone (PSL) for the acquired FVI.

\section{Case Report}

A 70-year-old woman was admitted to our hospital in February 1999 for the purpose of investigating an equivocal liver mass. Although angiography and needle biopsy were performed in July 1999 and May 2000, respectively, hepatocellular carcinoma (HCC) was not confirmed. Subsequently, follow-up treatment for HCV-related liver cirrhosis and hypertension was continued. Because laboratory tests revealed a high serum alanine aminotransferase (ALT) level (about $100 \mathrm{IU} / \mathrm{l})$, the patient was given ursodesoxycholic acid orally. Other medications included amlodipine, LIVACT granules, a mixture of vitamin B, L-aspartic acid calcium, and alphacalcidol were administered for the duration of her clinical course. At the beginning of April 2001, gingival and nasal bleeding occurred spontaneously. Because her condition did not improve in spite of the administration of 4 units of fresh frozen plasma, she was hospitalized in April 2001. She had an appendectomy 50 years previously; however,

\footnotetext{
${ }^{1}$ Department of Internal Medicine, Tokyo Women's Medical University Medical Center East, Tokyo and 2 Department of Surgical Pathology, Tokyo Women's Medical University Medical Center East, Tokyo

Received for publication November 24, 2006; Accepted for publication January 22, 2007

Correspondence to Dr. Hitoshi Endo, endogm@dnh.twmu.ac.jp
} 
Table 1. Laboratory Findings on Admission

\begin{tabular}{|c|c|c|c|c|}
\hline \multirow{2}{*}{$\begin{array}{l}\text { Peripheral blood } \\
\text { WBC } 5500 / \mu 1\end{array}$} & \multicolumn{2}{|c|}{ Blood chemistry } & \multicolumn{2}{|l|}{ Serology } \\
\hline & TP & $8.2 \mathrm{~g} / \mathrm{dl}$ & \multirow{2}{*}{\multicolumn{2}{|c|}{$\begin{array}{l}\text { HBV ; sAg (-), sAb (+/-), } \\
\text { eAg (-), eAg (+/-) }\end{array}$}} \\
\hline RBC $298 \times 10^{4} / \mu 1$ & Alb & $3.2 \mathrm{~g} / \mathrm{dl}$ & & \\
\hline $9.8 \mathrm{~g} / \mathrm{dl}$ & ZTT & $39.2 \mathrm{~K}-\mathrm{U}$ & \multicolumn{2}{|c|}{ cAb (+) $100 \%(\times 20098.1 \%)$} \\
\hline $28.6 \%$ & AST & $67 \mathrm{IU} / 1$ & \multicolumn{2}{|l|}{ HCV Ab (+) } \\
\hline $16.2 \times 10^{4} / \mu 1$ & $\begin{array}{l}\text { ALT } \\
\text { LDH }\end{array}$ & $\begin{array}{l}58 \mathrm{IU} / 1 \\
222 \mathrm{IU} / 1\end{array}$ & \multicolumn{2}{|l|}{ ANA $\times \mathbf{4 0}$} \\
\hline Coagulation test & ALP & $241 \mathrm{IU} / 1$ & \multicolumn{2}{|c|}{ Anti-cardiolipin Ab IgM 0.7} \\
\hline PT $\quad 46.6 \mathrm{sec}$ & $\gamma$-GTP & $39 \mathrm{IU} / 1$ & \multirow{2}{*}{\multicolumn{2}{|c|}{$\begin{array}{c}\text { IgG } 1.0 \\
\text { Anti-CL. } \beta \text { 2-GPI Ab } 4.9 \mathrm{U} / \mathrm{ml}\end{array}$}} \\
\hline APTT > $>212.0 \mathrm{sec}$ & LAP & $148 \mathrm{IU} / \mathrm{l}$ & & \\
\hline $235 \mathrm{mg} / \mathrm{dl}$ & ChE & $118 \mathrm{IU} / \mathrm{l}$ & \multicolumn{2}{|c|}{ Cryoglobulin (+/-) } \\
\hline $\begin{array}{ll}\text { TT } & 42.7 \% \\
\text { HPT } & 61.8 \%\end{array}$ & $\begin{array}{l}\text { T.B. } \\
\text { D.B. }\end{array}$ & $\begin{array}{l}0.8 \mathrm{mg} / \mathrm{dl} \\
0.3 \mathrm{mg} / \mathrm{dl}\end{array}$ & \multicolumn{2}{|c|}{ Coagulation factor assays } \\
\hline \multirow{2}{*}{$2.6 \mu \mathrm{g} / \mathrm{ml}$} & BUN & $13.8 \mathrm{mg} / \mathrm{dl}$ & Factor II & $69 \%$ \\
\hline & Cre & $0.55 \mathrm{mg} / \mathrm{dl}$ & Factor $\mathrm{V}$ & $<3 \%$ \\
\hline Tumor marker & T.Chol. & $135 \mathrm{mg} / \mathrm{dl}$ & Factor VII & $78 \%$ \\
\hline $73.7 \mathrm{ng} / \mathrm{ml}$ & \multirow{6}{*}{$\begin{array}{l}\mathrm{FBS} \\
\mathrm{NH}_{3}\end{array}$} & \multirow{6}{*}{$\begin{array}{l}88 \mathrm{mg} / \mathrm{dl} \\
47 \mu \mathrm{g} / \mathrm{ml}\end{array}$} & Factor VIII & $>200 \%$ \\
\hline AFP-L3 $\quad 2.4 \%$ & & & Factor IX & $77 \%$ \\
\hline PIVKA II 9 mAU/ml & & & Factor $\mathrm{X}$ & $97 \%$ \\
\hline & & & Factor XI & $67 \%$ \\
\hline & & & Factor XII & $118 \%$ \\
\hline & & & \multicolumn{2}{|c|}{ Factor $\mathrm{V}$ inhibitor $2 \mathrm{BU}$} \\
\hline
\end{tabular}

there was no personal or family history of bleeding disorders. She had been a smoker for more than 40 years.

On admission, the patient appeared pale but was otherwise in good health. Hepatomegaly, vascular spiders of the skin, and palmer erythemas of both hands were evident at the physical examination. The laboratory findings are summarized in Table 1. Coagulation studies revealed prothrombin time (PT) of $46.6 \mathrm{sec}$ and activated partial thromboplastin time (APTT) of $>212.0 \mathrm{sec}$, and hepaplastin test (HPT) of $61.8 \%$. Coagulation factor assays showed a decrease in the FV activity of $<3 \%$. The titration of a specific inhibitor for FV demonstrated 2 Bethesda units (BU). Abnormal findings associated with her anemia or liver dysfunction were evident. Autoantibodies, such as anti-nuclear antibody (ANA) of $\times 40$, lupus anticoagulant of 1.60 (normal range; <1.3), and anti-cardiolipin, $\beta 2-\mathrm{GPI}$, antibody of 4.9 $\mathrm{U} / \mathrm{ml}$ (normal range; <3.5) suggested the autoimmunity as an underlying condition. A chest X-ray revealed almost normal findings. Hepatosplenomgaly was demonstrated on an abdominal CT scan: otherwise the existence of HCC was still uncertain.

The clinical course is illustrated in Fig. 1. At the end of May, the patient complained of diffuse swelling in her left calf, which was diagnosed as hematoma after an MRI examination. In the absence of a spontaneous recovery from a bleeding tendency, PSL $(0.8 \mathrm{mg} / \mathrm{kg} /$ day $)$ administration was started on the following day. She began to improve in a few days and the bleeding tendency was eliminated. On the 7th day of PSL treatment, coagulation studies revealed marked recovery; PT of 19.6 seconds and APTT of 46.2 seconds. FVI became undetectable on the 9th day. The PSL dosage was progressively reduced biweekly. Coagulation markers subsequently remained stable with an FV activity of $73 \%$. She was discharged at the end of June.

At the end of August, the PSL dosage was increased to $30 \mathrm{mg} /$ day because her PT was prolonged again. In mid-
September 2001, she was re-hospitalized because of chest pain, a fever, cough, and excessive sputum production. Chest X-rays revealed a mass lesion on her right hilum. A CT scan and tumor markers suggested a lung cancer $(5 \mathrm{~cm}$ maximum on CT scan), while a bronchoscopic study provided uncertain results. However, specific treatment was avoided because of her concomitant diseases. During the follow-up period, superior vena cava syndrome developed in mid-November and the patient expired at the end of December. She had received $20 \mathrm{mg} /$ day of PSL and her FVI had remained undetectable in December.

A summary of the autopsy examination is as follows: 1.) lung cancer (well differentiated squamous cell carcinoma), $8.5 \times 5 \times 9 \mathrm{~cm}$ in size, adjacent to the right main bronchus, with metastases to the pericardium and lymph nodes of the right hilum and mediastinum (Fig. 2a and b); 2.) liver cirrhosis with moderately differentiated $\mathrm{HCC}$ of $\mathrm{S} 8,0.8 \mathrm{~cm}$ in size (Fig. 2c, d, and e); 3.) cardiomegaly and arteriosclerosis due to hypertension.

\section{Discussion}

Knöbl and Lechner described that malignant diseases were found in $16.3 \%$ of 105 cases with FVIs (4). The underlying malignancies include multiple myeloma (4), buccal epidermoid carcinoma (5), colon cancer (6-8), pancreatic cancer (9), central nervous system tumor (10), anaplastic carcinoma (11), prostatic cancer $(5,7)$, metastatic liver cancer $(12)$, and HCC $(13,14)$. Among those cases, only two with double cancers were documented. Bayani et al reported a case of FVI with buccal epidermoid carcinoma and prostatic cancer (5). Okajima et al introduced a case with prostatic and colonic cancers (7). Thus, a combination of lung cancer and $\mathrm{HCC}$, such as that seen in the present case, is the first instance of double cancers with FVIs. FVIs had been associated with conditions such as surgical procedures 


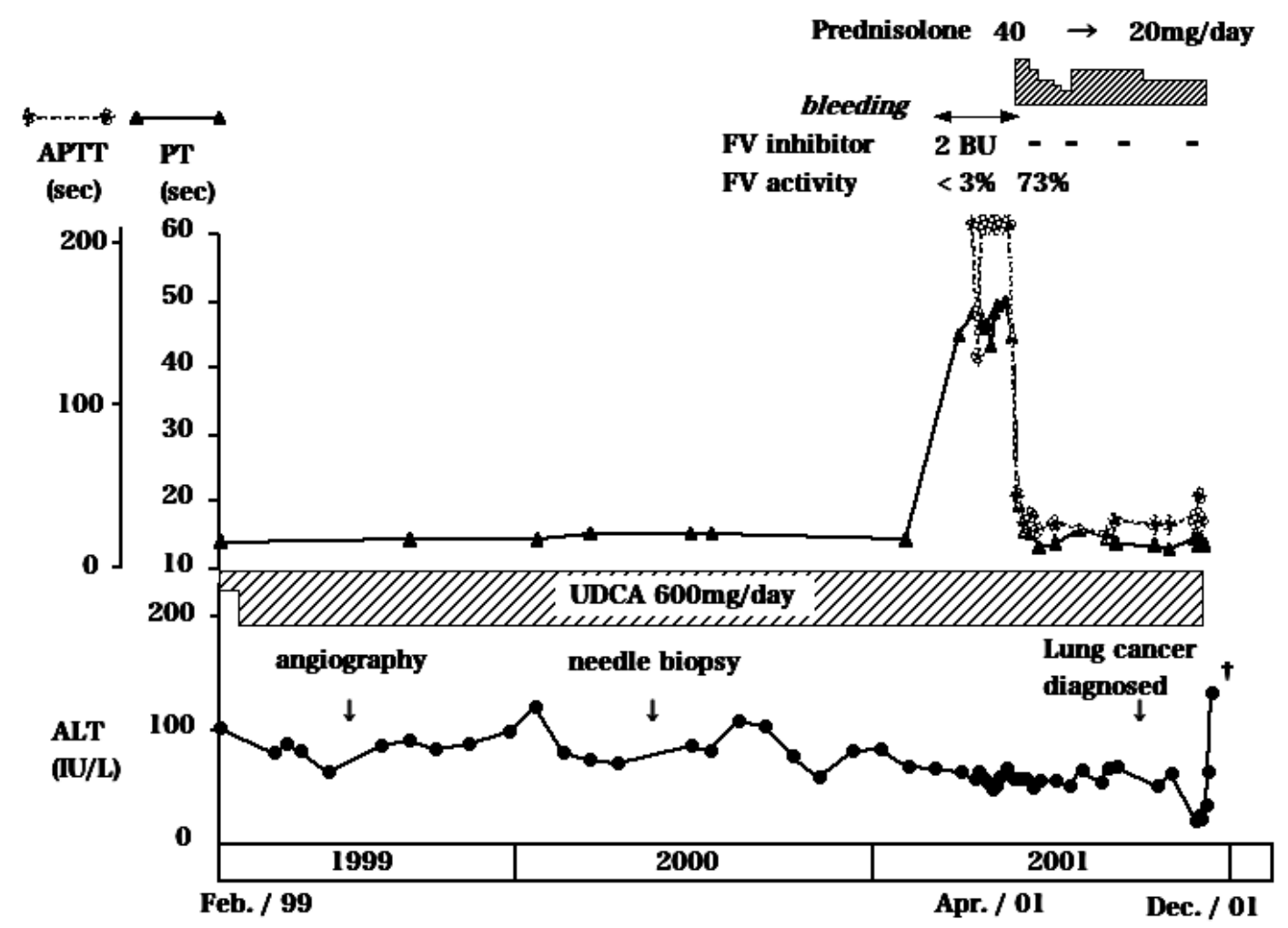

Figure 1. Clinical course. In 1999, HCC in S8 of the liver might have been already growing, while the angiography and needle biopsy could not demonstrate its existence. Besides, it was thought that the lung cancer had appeared simultaneously with the FVIs, suggesting a relationship between the two from a chronological point of view. ALT: alanine aminotransferase, APTT: activated partial thromboplastin time, BU: Bethesda units, FV: factor V, PT: prothrombin time, UDCA: ursodesoxycholic acid.

and exposure to antibiotics in most cases; but our patient had neither undergone a surgical procedure nor received antibiotics.

Because a high signal intensity area $(1 \mathrm{~cm}$ in diameter, figure not shown) in S8 of the liver, demonstrated by ferumoxide-enhanced MRI examination in May 1999, was considered retrospectively to be a tumor, the patient might have developed the HCC in 1999. On the other hand, the cancer of the right lung was found by a chest CT scan in September 2001. According to the formula of doubling time $(15,16)$, which is calculated from two tumor sizes of the initial point $(5 \mathrm{~cm}$ in September) and the final point $(9 \mathrm{~cm}$ in December), the lung cancer was estimated to be at least 2 $\mathrm{cm}$ in diameter in April 2001. However, we could not identify the tumor, probably because it was hidden by the mediastinal shadow on the chest X-ray film at that time. Because the first bleeding event occurred in April 2001, the lung cancer might have developed concomitantly, suggesting the relationship between FVI and lung cancer. It has been proposed that malignancies may cause the production of autoantibodies as paraneoplastic syndromes (17). Bayani et al (5) also referred to a link between cancer and autoimmunity and discussed the malignancy as a hypothetical cause of FVI.

In addition, a causal relationship between HCV-related liver diseases and FVIs can be considered. Generally, HCV can infect immune cells such as T- and B-cells, thus modulating the immune response (18). In fact, $\mathrm{HCV}$ infection has been shown to be associated with various autoimmune disorders (19). One case of HCV infection with FVIs (such as the present case) has been reported, in which a causal relationship was obscure (13). Moreover, a previous study showed the association of anti-phospholipid antibodies and FVIs (20). We observed the development of antiphospholipid antibodies in the present case also, suggesting that an autoimmune mechanism may be involved in the development of FVIs in this patient with an $\mathrm{HCV}$ infection and malignancy.

In terms of therapy for FVIs with bleeding tendency, several modalities - such as platelet concentrates, intravenous immunoglobulin, plasma exchange, and immunosuppressants (e.g., corticosteroids, cyclophosphamide, and cyclosporine A)-have been employed $(5,9,21)$. Streiff and Ness reviewed the treatment of patients with symptomatic FVI and recommended steroid therapy as an initial trial for those with mild-to-moderate bleeding because of the higher efficacy of corticosteroids with $74 \%$ success (3). Actually, PSL therapy was effective in suppressing FVI in the present case. Although coagulation markers such as PT and APTT indicated a transient deterioration when the PSL dosage was re- 

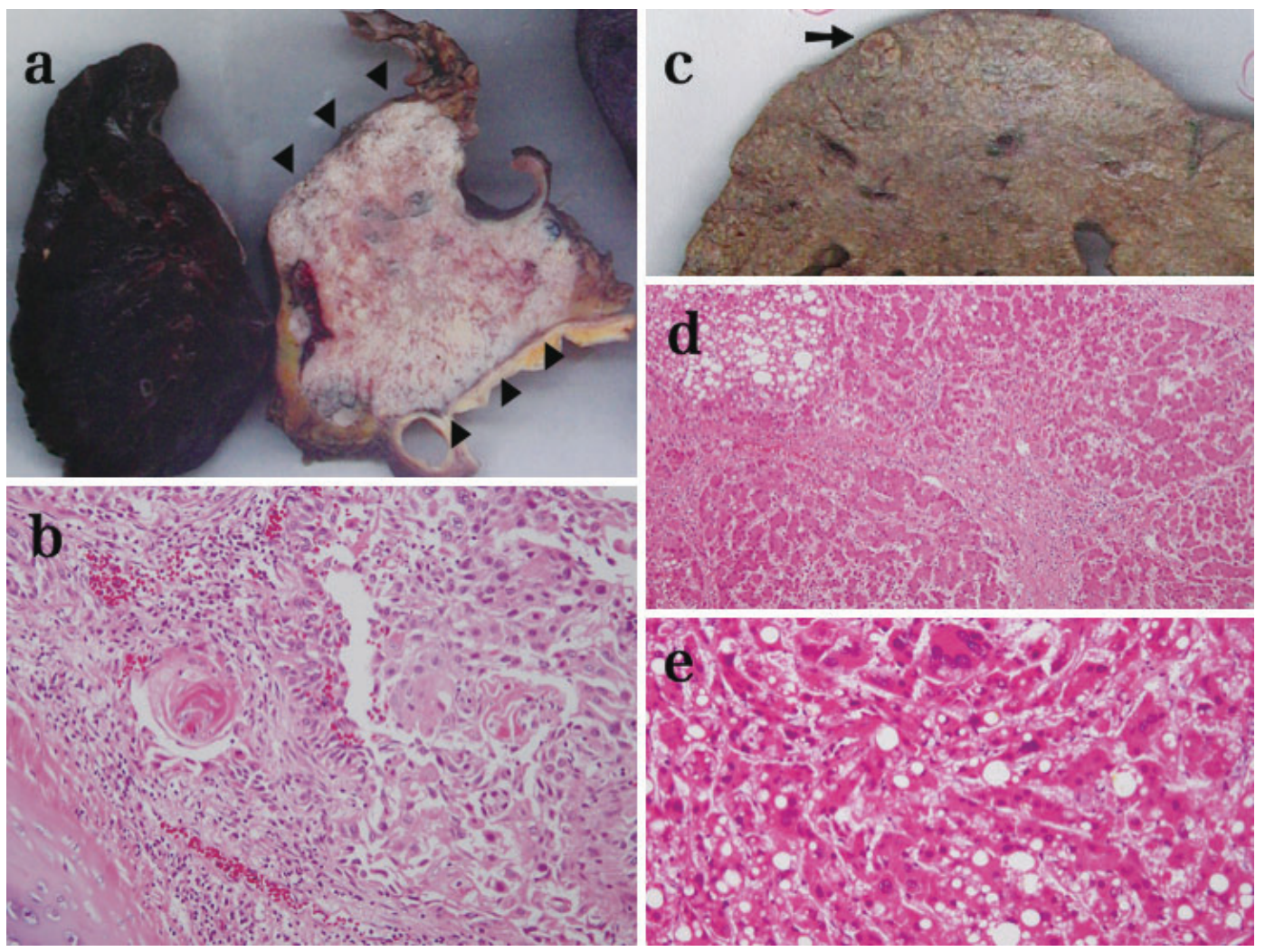

Figure 2. Autopsy findings. (a) Macroscopic findings of lung cancer adjacent to the right main bronchus, measuring $8.5 \times 5 \times 9 \mathrm{~cm}$ (arrow heads). (b) Its histopathological subtype is well-differentiated squamous cell carcinoma with cancer pearl (HE stain). (c) Macroscopic findings of the liver. HCC in S8 (arrow) is shown. (d) Histopathological examination shows liver cirrhosis (HE stain).

(e) HCC is moderately differentiated (HE stain).

duced, a re-escalation of PSL dosage led to a rapid normalization of abnormal coagulation values. Therefore, steroid therapy should be considered as an initial trial for FVI patients who are also suffering from malignancies.

The patient succumbed to the advanced lung cancer, although a complete resolution of FVI was maintained by
PSL therapy. Because the existence of a malignancy in patients with FVIs may determine their prognosis, the screening of malignancies as underlying diseases is very important. An accumulation of such cases with a detailed investigation may contribute to clarify the mechanism by which FVIs develop in patients with malignancies.

\section{References}

1. Hörder MH, Sokal G. Effect of factor V on formation of plasma thromboplastin. Acta Haematol 14: 294-302, 1955 (in German).

2. Ferguson JH, Johnston CL Jr, Howell DA. A circulating inhibitor (Anti-AcG) specific for the labile factor- $\mathrm{V}$ of the blood-clotting mechanism. Blood 13: 382-397, 1958.

3. Streiff MB, Ness PM. Acquired FV inhibitors: a needless iatrogenic complication of bovine thrombin exposure. Transfusion 42: 18-26, 2002.

4. Knöbl P, Lechner K. Acquired factor V inhibitors. Baillieres Clin Haematol 11: 305-318, 1998.

5. Bayani N, Rugina M, Haddad-Vergnes L, Lelong F. High-titer acquired factor $\mathrm{V}$ inhibitor responsive to corticosteroids and cyclophosphamide in a patient with two malignant tumors. Am J Hematol 71: 33-36, 2002.

6. Feinstein DI, Rapaport SI, McGehee WG, Patch MJ. Factor V anticoagulants: clinical, biochemical, and immunological observations. J Clin Invest 49: 1578-1588, 1970.

7. Okajima A, Horii J, Nasu K, et al. Factor V inhibitor with double cancer. Jpn J Clin Hematol 30: 514-519, 1989 (in Japanese, Abstract in English).
8. Abe T, Kazama M, Itokazu K, et al. A case of sigmoid cancer who aquired factor $\mathrm{V}$ inhibitor producibility and treated with factor VIII inhibitor bypassing activity preparation FEIBA-with bibliographic review. Jpn J Clin Hematol 21: 1664-1173, 1980 (in Japanese, Abstract in English).

9. Kuto M, Izuchi Y, Deguchi K, Morito T, Lee C, Wada H. An inhibitor against factor $\mathrm{V}$ occurring postoperatively in case of pancreatic cancer. Acta Haematol Jpn 44: 938-950, 1981.

10. Kamphuisen PW, Haan J, Rosekrans PC, Van Der Meer FJ. Deepvein thrombosis and coumarin skin necrosis associated with a factor V inhibitor with lupus-like features. Am J Hematol 57: 176178, 1998.

11. Nesheim ME, Nichols WL, Cole TL, et al. Isolation and study of an acquired inhibitor of human coagulation factor V. J Clin Invest 77: 405-415, 1986

12. Cruickshank MK, Black J, Wall W. Development of a factor V and thrombin inhibitor following partial hepatic resection and the use of topical thrombin concentrate. Clin Lab Haematol 16: 187190, 1994.

13. Nakagoshi R, Takamiya $O$, Nakata $S$, et al. A case positive for the 
inhibitor for coagulation factor V. Rinsho Byori 47: 971-975, 1999 (in Japanese, Abstract in English).

14. Leroy-Matheron $\mathrm{C}$, Mallat $\mathrm{A}$, Duvoux $\mathrm{C}$, et al. Inhibitor against coagulation factor $\mathrm{V}$ after liver transplantation. Transplantation $\mathbf{6 8}$ : 1054-1056, 1999.

15. Collins VP, Loeffler RK, Tivey H. Observation on growth rates of human tumors. Am J Roentgenol 76: 988-1000, 1956.

16. Schwartz M. A biomathematical approach to clinical tumor growth. Cancer 14: 1272-1294, 1961.

17. Abu-Shakra M, Buskila D, Ehrenfeld M, et al. Cancer and autoimmunity: autoimmune and rheumatic features in patients with malignancies. Ann Rheum Dis 60: 433-441, 2001.
18. Fornasieri A, Bernasconi $P$, Ribero ML, et al. Hepatitis $C$ virus in lymphocyte subsets and in B lymphocytes expressing rheumatoid factor cross-reacting idiotype in type II mixed cryoglobulinaemia. Clin Exp Immunol 122: 400-403, 2000.

19. McMurray RW, Elbourne K. Hepatitis $C$ virus infection and autoimmunity. Semin Arthritis Rheum 26: 689-701, 1997.

20. Favaloro EJ, Posen J, Ramakrishna R, et al. Factor V inhibitors: rare or not so uncommon? A multi-laboratory investigation. Blood Coagul Fibrinolysis 15: 637-647, 2004.

21. Fu YX, Kaufman R, Rudolph AE, Collum SE, Blinder MA. Multimodality therapy of an acquired factor $\mathrm{V}$ inhibitor. Am J Hematol 51: 315-318, 1996.

(C) 2007 The Japanese Society of Internal Medicine http://www.naika.or.jp/imindex.html 